\title{
Efektifitas Terapi Senam Stroke Terhadap Perbaikan Kemampuan Fungsional Pasien Paska Stroke
}

\author{
Neri Basmara ${ }^{a}$, Reni Prima Gusty ${ }^{b}$, Ema Julita $^{a}$ \\ ${ }^{\text {a }}$ RSUP. Dr. M Djamil Padang \\ b Program Studi Ilmu Keperawatan Fakultas Kedokteran Unand \\ E-mail:nhe_ree@yahoo.co.id
}

\begin{abstract}
Stroke exercise physical therapy is routinely performed in Dr M Djamil Hospital that purpose to increase functional abilities of stroke patients.This study aimed to determine the difference on effectiveness of exercise therapy twice aweek and 3 times a week in improving the functional abilities of stroke patients. The study was conducted for 4 weeks using a quasi experimental design with non-randomized approach without pretest-posttest control group design. Sample was 22 respondents who experienced ischemic stroke. The instrument used for data collection is a sheet measuring functional ability based on the Barthel index scale. The analyzes were performed by using the Shapiro-Wilk normality test, paired t test and mannwhitney test.The results showed that exercise therapy can improve stroke patient's functional ability after stroke with the mean of therapy exercise stroke $2 x$ and $3 x$ a week is 9,636 $(p=0,000)$ and 10,909 ( $p=0,000)$. However, the differences increase in functional ability between two groups of participants was not statistically significant ( $p$ value =0,198). Based on the findings of this study, it is suggested that management of the department of Dr. M. Djamil Padang guidelines for this therapy in the form of SOP, and the frequency of stroke therapy is performed calisthenics $3 x$ a week for optimum improvement of functional ability can be felt by patients who follow this therapy.
\end{abstract}

Keywords: stroke exercise, improved functional ability, post-stroke patients

\begin{abstract}
Abstrak : Senam stroke merupakan terapi fisik rutin dilakukan di Rumah Sakit Umum Pusat Dr M Djamil Padang guna meningkatkan kemampuan fungsional pasien paska stroke. Penelitian bertujuan untuk mengetahui perbedaan efektifitas terapi senam stroke $2 \mathrm{x}$ seminggu dan $3 \mathrm{x}$ seminggu selama 4 minggu guna meningkatkan kemampuan fungsional pasien pasca stroke. Rancangan penelitian menggunakan quasi eksperimen dengan pendekatan non random pretestposttest tanpa kontrol. Sampel penelitian 22 orang responden yang mengalami stroke iskemia. Instrumen pengumpulan data adalah lembaran pengukuran kemampuan fungsional yang berpedoman pada skala Indeks Barthel. Analisa data menggunakan uji normalitas Shapiro-wilk, uji t berpasangan dan uji mann whitney. Hasil penelitian menunjukkan bahwa terapi senam stroke dapat meningkatkan kemampuan fungsional pasien paska stroke dengan rerata peningkatan pada senam stroke $2 x$ dan $3 x$ seminggu adalah 9,636 $(\mathrm{p}=0,000)$ dan 10,909 $(\mathrm{p}=0,000)$. Akan tetapi, perbedaan peningkatan kemampuan fungsional antara kedua kelompok partisipan tersebut secara statistik tidak signifikan ( $p$ value $=0,198$ ). Berdasarkan temuan penelitian ini, disarankan agar manajemen RSUP DR. M. Djamil Padang membuat panduan untuk terapi ini dalam bentuk SOP, dan frekwensi terapi senam stroke tersebut dilakukan 3x seminggu agar perbaikan optimum kemampuan fungsional dapat dirasakan oleh pasien yang mengikuti terapi ini.
\end{abstract}

Kata kunci: senam stroke, perbaikan kemampuan fungsional, pasien paska stroke

Stroke adalah cedera vaskuler akut pada otak atau suatu cedera yang berat dan mendadak pada pembuluh-pembuluh darah otak (Soeharto, 2002). Pada saat ini, penyakit stroke telah menjadi masalah neurologik primer di dunia. Di Amerika 
Serikat, stroke menempati posisi ketiga sebagai penyakit utama yang menyebabkan kematian setelah penyakit jantung dan kanker. Setiap tahun, terdapat laporan 700.00 kasus stroke, dengan perincian 500.000 merupakan kasus serangan stroke pertama dan 200.000 kasus stroke lainnya merupakan serangan stroke berulang. Sedangkan di Indonesia sendiri, 28,5\% penderita stroke meninggal dunia dan sisanya mengalami kelumpuhan atau kecacatan. Hanya $15 \%$ saja yang dapat sembuh total dari serangan stroke atau kecacatan (Sutrisno, 2007).

Samino (2008 dikutip dari Anggleni, 2010) mengungkapkan bahwa proses kesembuhan utama yang harus dijalani penderita stroke adalah melalui penyembuhan dengan obat-obatan di rumah sakit serta melalui rehabilitasi. Dengan program rehabilitasi yang tepat, $80 \%$ dari penderita stroke dapat berjalan tanpa bantuan, $70 \%$ dapat melakukan aktifitas mengurus diri sendiri, dan 30\% lainnya dapat kembali bekerja (Parjoto, 1999 dikutip dalam Widyatama, 2008). Salah satu bentuk terapi rehabilitasi yang sering digunakan adalah program latihan fisik atau fisioterapi. Dalam terapi ini, penderita stroke melakukan latihan fungsional dan identifikasi kunci utama pada tugas-tugas motorik tertentu seperti duduk, berbicara, atau berjalan. Setiap tugas motorik dianalisis, ditentukan komponen-komponen yang tidak dapat dikerjakan, melatih penderita untuk melakukan hal-hal tersebut, serta memastikan latihan ini dilakukan pada aktifitas sehari-hari pasien (Widiyanto, 2009).

Selain itu, program latihan fisik atau fisioterapi tersebut difokuskan pada aktifitas sehari-hari seperti makan dan minum, mandi, berpakaian, berhias, menggunakan toilet, kontrol buang air kecil dan besar, berpindah tempat, mobilitas jalan, dan menggunakan tangga (Wirawan, 2009). Bahkan, Soegiarto (2004) mengungkapkan bahwa latihan fisik selain bermanfaat untuk kebugaran tubuh, juga bermanfaat untuk mengstabilkan fungsi sistem organ manusia.
Latihan fisik juga memainkan peran penting dalam pemeliharaan fungsi otot dalam tubuh manusia (Berwald, 2007). Telaah literatur yang peneliti lakukan menunjukan bahwa baru treadmill training and water based aerobic (pada riset Boersma et al., nd), aerobic exercise training (pada riset Pang et al., 2006), serta fisioterapi (pada riset Yulinda, 2009) yang telah terbukti secara empiris mampu meningkatkan kemampuan fungsional pasien. Sedangkan riset dengan tujuan serupa dengan menggunakan senam stroke belum ditemukan.

Peneliti berpendapat bahwa senam stroke juga punya potensi yang sama dengan terapi fisik lainnya untuk digunakan memperbaiki kemampuan fungsional pasien paska stroke. Soeparman (2004) mengungkapkan senam stroke merupakan salah satu bentuk latihan fisioterapi yang disusun sedemikian rupa untuk dapat memberikan rangsangan kepada beberapa reseptor yang akan dibawa ke otak untuk diproses dan menghasilkan output berupa gerakan yang terkoordinasi. Ketiga bagian senam stroke ini (pemanasan, inti, dan pendinginan) lebih banyak mengggunakan organ tangan, kepala, leher, pundak, pantat, lutut, tungkai, dan kaki. Peningkatan kekuatan otot pada masing-masing organ yang diberi latihan pemanasan dan gerakan inti tersebut akan meningkatkan kemampuan fungsional pasien dalam melakukan aktifitas sehari-harinya seperti makan, mencuci muka, menggosok gigi, mandi, berpakaian, dan berjalan.

Selain itu, ketika melakukan survey awal pelaksanaan senam stroke di IRM RSUP Dr M Djamil Padang, peneliti memperoleh informasi bahwa peserta senam stroke tidak pernah diberikan catatan tentang sejauh mana kemajuan/perbaikan kemampuan fungsional mereka setelah menjalani senam stroke tersebut. Therapist yang ada di IRM RSUP DR. M. Djamil Padang juga membenarkan belum ada pencatatan yang sistematis tentang kemajuan dari kemampuan fungsional pasien pasca stroke yang menjalani terapi senam stroke. Ketika peneliti mencoba 
untuk mendokumentasikan sendiri perkembangan kemampuan fungsional 6 orang pasien yang dirahasiakan identitasnya, ternyata 4 dari 6 orang pasien (67\%) tersebut mengalami peningkatan kemampuan fungsional sebesar 5 poin. Temuan ini menurut hemat peneliti merupakan indikasi bahwa ada pengaruh positif antara senam stroke dengan perbaikan kemampuan fungsional pasien pasca stroke.

Penelitian ini bertujuan untuk mendapatkan bukti empiris efektifitas terapi senam stroke terhadap perbaikan kemampuan fungsional pasien paska stroke.

\section{METODE}

Jenis penelitian ini adalah kuasi eksperimen dengan pendekatan non randomized comparison group pretestposttest design (Loiselle et al., 2011). Pada tiap-tiap kelompok treatment dilakukan pretest serta posttest untuk mengukur pengukuran kemampuan fungsional pasien antara sebelum dan sesudah menjalani terapi senam stroke $2 x$ serta $3 x$ seminggu. Tempat penelitian adalah Instalasi Rehabilitasi Medik (IRM) RSUP Dr. M. Djamil Padang. Adapun waktu penelitian adalah 4 minggu, yaitu tanggal 3-29 Oktober 2011.

Sampel penelitian adalah 22 orang pasien paska stroke yang berkunjung ke IRM RSUP Dr. M. Djamil Padang, yang diambil berdasarkan teknik accidental sampling serta telah memenuhi kriteria inklusi dan kriteria ekslusi yang ditetapkan. Adapun kriteria inklusi yang digunakan dalam penelitian ini adalah sebagai berikut: Semua partisipan adalah pasien pasca stroke iskemia, kondisi umum yang stabil (TD $\leq 140 / 90 \mathrm{mmHg}$, tidak pusing, dan RR: $16-24 \mathrm{x} / \mathrm{menit}$ ), penderita yang mengalami hemiparesis. Penelitian ini tidak mengikutsertakan pasien yang menderita afasia global.

Pengambilan data dilakukan pada 22 orang pasien paska stroke yang dibagi dalam 2 kelompok. Kelompok pertama (terdiri dari 11 orang) menjalani terapi senam stroke $2 \mathrm{x}$ seminggu pada hari Senin dan Kamis pagi pukul 09.30-10.30 WIB. Sedangkan kelompok kedua (juga terdiri dari 11 orang) menjalani terapi senam stroke $3 x$ seminggu pada hari Senin, Kamis, dan Sabtu sore pukul 16.30- 17.30 WIB. Waktu untuk tiap sesi terapi senam stroke adalah 60 menit.

Instrumen yang digunakan untuk pengambilan data dalam penelitian ini adalah lembar pengukuran kemampuan fungsional dengan menggunakan Indeks Barthel. Data yang diterima selanjutnya diolah secara univariat menggunakan distribusi frekuensi, sebelum dilanjutkan dengan uji bivariate, terlebih dahulu dilakukan uji Saphiro Wilk untuk melihat normalitas sebaran data. Pengolahan data dilakukan secara bivariat menggunakan uji T berpasangan, dan uji Mann-Whitney.

Uji $\mathrm{T}$ berpasangan dilakukan untuk menganalisa perbedaan skor indeks Barthel sebelum dan sesudah senam stroke $2 \mathrm{x}$ seminggu dan perbedaan skor indeks Barthel sebelum dan sesudah terapi senam 3x seminggu. Uji Mann-Whitney dilakukan untuk menganalisa perbedaan selisih skor indeks Barthel sebelum dan sesudah terapi senam stroke $2 \mathrm{x}$ seminggu dan selisih skor Indeks Barthel sebelum dan sesudah terapi senam stroke $3 \mathrm{x}$ seminggu.

\section{HASIL DAN PEMBAHASAN}

Data pada Tabel 1 dan Tabel 2 di bawah ini memperlihatkan bahwa terapi senam stroke $2 \mathrm{x}$ seminggu mampu memperbaiki kemampuan fungsional pasien. Hal ini terlihat dari rerata kemampuan fungsional pasien yang diukur menggunakanan Indeks Barthel pada saat posttest $(86,4)$ lebih tinggi 9,6 poin daripada saat pretest $(78,8)$. Peningkatan tersebut signifikan secara statisitik ( $p$-value = 0,000). Perbaikan kemampuan fungsional yang paling pesat pada pasien kelompok ini terdapat pada aktifitas berpakaian, aktifitas berjalan pada permukaan datar, dan aktifitas di toilet. Secara akumulatif, 5 dari 11 orang pasien saja mampu mendapatkan perbaikan optimum kemampuan fungsional setelah menjalani terapi senam stroke $2 x$ seminggu, 
yang tercermin dari jumlah pasien yang mampu memperoleh skor maximum Indeks Bartel (10 atau 15) atau mampu melakukan secara mandiri tiap-tiap aktifitas hidup harian yang diobservasi.

Tabel 1. Rerata Kemampuan Fungsional Pasien Pasca Stroke Sebelum Dan Sesudah Melakukan Terapi Senam Stroke 2x Seminggu

\begin{tabular}{lccccccc}
\hline \multicolumn{2}{c}{ Kemampuan Fungsional } & Mean & SD & P-value & N \\
\hline - Sebelum & terapi & senam & stroke & 76,8 & 5,6 & & \\
$\begin{array}{l}\text { (pretest) } \\
\text { Sesudah }\end{array}$ & terapi & senam & stroke & 86,4 & 7,2 & 0,000 & 11 \\
(posttest) & & & & & & & \\
\hline
\end{tabular}

Tabel 2. Kemampuan Fungsional Pasien Sebelum dan Sesudah Mengikuti Terapi Senam Stroke 2x Seminggu

\section{Terapi senam stroke $2 x$ seminggu}

No. Aktifitas Kemampuan Fungsional

F ${ }^{\text {Pretest }} \% \quad$ F ${ }^{\text {Posttest }} \%$

\begin{tabular}{|c|c|c|c|c|c|}
\hline 1. & $\begin{array}{l}\text { Makan } \\
\text { a. Dengan bantuan } \\
\text { b. Mandiri } \\
\text { Total }\end{array}$ & $\begin{array}{c}7 \\
4 \\
11\end{array}$ & $\begin{array}{c}63,6 \\
36,4 \\
\mathbf{1 0 0 , 0}\end{array}$ & $\begin{array}{c}5 \\
6 \\
11\end{array}$ & $\begin{array}{c}45,4 \\
54,6 \\
\mathbf{1 0 0 , 0}\end{array}$ \\
\hline 2. & $\begin{array}{l}\text { Transfer dari kursi roda ke tempat tidur } \\
\text { a. Dengan bantuan } \\
\text { b. Mandiri } \\
\text { Total }\end{array}$ & $\begin{array}{c}0 \\
11 \\
\mathbf{1 1}\end{array}$ & $\begin{array}{c}0 \\
100,0 \\
\mathbf{1 0 0 , 0}\end{array}$ & $\begin{array}{c}0 \\
11 \\
\mathbf{1 1}\end{array}$ & $\begin{array}{c}0 \\
100,0 \\
\mathbf{1 0 0}\end{array}$ \\
\hline 3. & $\begin{array}{l}\text { Kebersihan diri } \\
\text { a. Dengan bantuan } \\
\text { b. Mandiri } \\
\text { Total }\end{array}$ & $\begin{array}{c}0 \\
11 \\
\mathbf{1 1}\end{array}$ & $\begin{array}{c}0 \\
100,0 \\
\mathbf{1 0 0}\end{array}$ & $\begin{array}{c}0 \\
11 \\
\mathbf{1 1}\end{array}$ & $\begin{array}{c}0 \\
100,0 \\
\mathbf{1 0 0 , 0}\end{array}$ \\
\hline 4. & $\begin{array}{l}\text { Aktifitas di toilet } \\
\text { a. Dengan bantuan } \\
\text { b. Mandiri } \\
\text { Total }\end{array}$ & $\begin{array}{c}5 \\
6 \\
11 \\
\end{array}$ & $\begin{array}{c}45,4 \\
54,6 \\
\mathbf{1 0 0 , 0}\end{array}$ & $\begin{array}{c}1 \\
10 \\
\mathbf{1 1}\end{array}$ & $\begin{array}{c}9,1 \\
90,9 \\
\mathbf{1 0 0 , 0}\end{array}$ \\
\hline 5. & $\begin{array}{l}\text { Mandi } \\
\text { a. Dengan bantuan } \\
\text { b. Mandiri } \\
\text { Total }\end{array}$ & $\begin{array}{c}0 \\
11 \\
\mathbf{1 1}\end{array}$ & $\begin{array}{c}0 \\
100,0 \\
\mathbf{1 0 0 , 0}\end{array}$ & $\begin{array}{c}0 \\
11 \\
\mathbf{1 1}\end{array}$ & $\begin{array}{c}0 \\
100,0 \\
\mathbf{1 0 0 , 0}\end{array}$ \\
\hline 6. & $\begin{array}{l}\text { Berjalan pada permukaan datar } \\
\text { a. Dengan bantuan } \\
\text { b. Mandiri } \\
\text { Total }\end{array}$ & $\begin{array}{c}9 \\
2 \\
11\end{array}$ & $\begin{array}{c}81,8 \\
18,2 \\
\mathbf{1 0 0 , 0}\end{array}$ & $\begin{array}{c}5 \\
6 \\
11\end{array}$ & $\begin{array}{r}45,4 \\
54,6 \\
\mathbf{1 0 0 , 0}\end{array}$ \\
\hline 7. & $\begin{array}{l}\text { Kemampuan naik turun tangga } \\
\text { a. Tidak mampu sama sekali } \\
\text { b. Dengan bantuan } \\
\text { c. Mandiri } \\
\text { Total }\end{array}$ & $\begin{array}{c}11 \\
0 \\
0 \\
\mathbf{1 1}\end{array}$ & $\begin{array}{c}100,0 \\
0 \\
0 \\
\mathbf{1 0 0 , 0}\end{array}$ & $\begin{array}{c}6 \\
5 \\
0 \\
\mathbf{1 1}\end{array}$ & $\begin{array}{c}54,5 \\
45,4 \\
0 \\
\mathbf{1 0 0 , 0}\end{array}$ \\
\hline
\end{tabular}




\begin{tabular}{llcccc}
\hline $\mathbf{8 .}$ & Berpakaian & & & & \\
& a. Dengan bantuan & 7 & 63,6 & 3 & 27,3 \\
b. Mandiri & 4 & 36,4 & 8 & 72,7 \\
& Total & $\mathbf{1 1}$ & $\mathbf{1 0 0 , 0}$ & $\mathbf{1 1}$ & $\mathbf{1 0 0}$ \\
\hline $\mathbf{9 .}$ & Mengontrol BAB & & & & \\
& a. Dengan bantuan & 0 & 0 & 0 & 0 \\
& b. Mandiri & 11 & 100,0 & 11 & 100,0 \\
$\quad$ Total & $\mathbf{1 1}$ & $\mathbf{1 0 0 , 0}$ & $\mathbf{1 1}$ & $\mathbf{1 0 0 , 0}$ \\
\hline $\mathbf{1 0 .}$ & Mengontrol BAK & & & \\
& a. Dengan bantuan & 0 & 0 & 0 & 0 \\
& b. Mandiri & 11 & 100,0 & 11 & 100,0 \\
& Total & $\mathbf{1 1}$ & $\mathbf{1 0 0}$ & $\mathbf{1 1}$ & $\mathbf{1 0 0 , 0}$ \\
\hline
\end{tabular}

Temuan penelitian ini konsisten dengan temuan riset Boersma et al., (nd), Pang et al., (2006), serta Yulinda (2009) tentang kontribusi positif terapi latihan fisik untuk memperbaiki kemampuan fungsional dan kemampuan motorik pasien paska stroke. Terjadinya peningkatan kemampuan fungsional pasien setelah menjalani terapi senam stroke $2 \mathrm{x}$ seminggu tersebut disebabkan karena terjadinya peningkatan massa otot, yang diperoleh setelah melakukan latihan fisik secara teratur. Parjoto dkk (1994) dan Sumaryanti (2005) mengungkapkan bahwa hasil adaptasi latihan fisik yang dilakukan secara teratur dalam kurun waktu tertentu adalah terjadinya peningkatan massa otot. Dengan adanya peningkatan massa otot, maka kekuatan otot meningkat. Peningkatan kemampuan otot inilah yang menyebabkan terjadinya peningkatan kemampuan fungsional pasien paska stroke, sehingga mereka lebih lincah bergerak dan cepat memberikan reaksi.
Data pada Tabel 3 dan Tabel 4 memperlihatkan bahwa terapi senam stroke $3 x$ seminggu lebih optimal memperbaiki kemampuan fungsional pasien. Hal ini terlihat dari rerata kemampuan fungsional pasien yang diukur menggunakanan indeks barthel pada saat posttest $(92,7)$ lebih tinggi 10,9 point daripada saat pretest $(81,8)$. Peningkatan tersebut signifikan secara statisitik $\quad(p$-value $=0,000) . \quad$ Perbaikan kemampuan fungsional yang paling pesat pada pasien kelompok ini terdapat pada aktifitas makan, aktifitas di toilet, berjalan pada permukaan datar, serta berpakaian. Secara akumulatif, 9 dari 11 orang pasien saja mampu mendapatkan perbaikan optimum kemampuan fungsional setelah menjalani terapi senam stroke $3 \mathrm{x}$ seminggu, yang tercermin dari jumlah pasien yang mampu memperoleh skor maximum indeks barthel (10 atau 15) atau mampu melakukan secara mandiri tiap-tiap aktifitas hidup harian yang diobservasi.

Tabel 3. Rerata Kemampuan Fungsional Pasien Pasca Stroke Sebelum Dan Sesudah Melakukan Terapi Senam Stroke 3x Seminggu

\begin{tabular}{lccccc}
\hline \multicolumn{2}{c}{ Kemampuan Fungsional } & Mean & SD & P-value & N \\
\hline - Sebelum terapi senam stroke (pretest) & 81,8 & 5,6 & & \\
- Sesudah terapi senam stroke & 92,7 & 6,1 & 0,000 & 11 \\
(posttest) & & & & & \\
\hline
\end{tabular}


Tabel 4. Kemampuan Fungsional Pasien Pasca Stroke Antara Sebelum dan Sesudah Mengikuti Terapi Senam Stroke 3x Seminggu

\begin{tabular}{|c|c|c|c|c|c|}
\hline \multirow{3}{*}{ No. } & \multirow{3}{*}{ Aktiftas Kemampuan Fungsional } & \multicolumn{4}{|c|}{ Terapi senam stroke $3 x$ seminggu } \\
\hline & & \multicolumn{2}{|c|}{ Pretest } & \multicolumn{2}{|c|}{ Posttest } \\
\hline & & $\mathbf{F}$ & $\%$ & $\mathbf{F}$ & $\%$ \\
\hline \multirow[t]{4}{*}{1.} & Makan & & & & \\
\hline & a. Dengan bantuan & 5 & 45,4 & 0 & 0 \\
\hline & b. Mandiri & 6 & 54,6 & 11 & 100,0 \\
\hline & Total & 11 & 100,0 & 11 & 100,0 \\
\hline \multirow[t]{4}{*}{2.} & $\begin{array}{l}\text { Transfer dari kursi roda ke tempat } \\
\text { tidur }\end{array}$ & 0 & 0 & 0 & 0 \\
\hline & a. Dengan bantuan & 11 & 100,0 & 11 & 100,0 \\
\hline & b.Mandiri & & & & \\
\hline & Total & 11 & $\mathbf{1 0 0 , 0}$ & 11 & 100,0 \\
\hline \multirow[t]{4}{*}{3.} & Kebersihan diri & & & & \\
\hline & a. Dengan bantuan & 0 & 0 & 0 & 0 \\
\hline & b.Mandiri & 11 & 100,0 & 11 & 100,0 \\
\hline & Total & 11 & 100,0 & 11 & 100,0 \\
\hline \multirow[t]{4}{*}{4.} & Aktifitas di toilet & & & & \\
\hline & a. Dengan bantuan & 4 & 36,4 & 0 & 0 \\
\hline & b. Mandiri & 7 & 63,6 & 11 & 100,0 \\
\hline & Total & 11 & 100,0 & 11 & 100,0 \\
\hline \multirow[t]{4}{*}{5.} & Mandi & & & & \\
\hline & a. Dengan bantuan & 0 & 0 & 0 & 0 \\
\hline & b.Mandiri & 11 & 100,0 & 11 & 100,0 \\
\hline & Total & 11 & 100,0 & 11 & 100,0 \\
\hline \multirow[t]{4}{*}{6.} & Berjalan pada permukaan datar & & & & \\
\hline & a. Dengan bantuan & 4 & 36,4 & 1 & 9,1 \\
\hline & b.Mandiri & 7 & 63,6 & 10 & 90,9 \\
\hline & Total & 11 & 100,0 & 11 & 100,0 \\
\hline \multirow[t]{5}{*}{7.} & Kemampuan naik turun tangga & & & & \\
\hline & a. Tidak mampu sama sekali & 11 & 100,0 & 5 & 45,4 \\
\hline & b. Dengan bantuan & 0 & 0 & 3 & 27,3 \\
\hline & c. Mandiri & 0 & 0 & 3 & 27,3 \\
\hline & Total & 11 & $\mathbf{0}$ & 11 & 100,0 \\
\hline \multirow[t]{4}{*}{8.} & Berpakaian & & & & \\
\hline & a. Dengan bantuan & 6 & 54,6 & 1 & 9,1 \\
\hline & b. Mandiri & 5 & 45,4 & 10 & 90,9 \\
\hline & Total & 11 & 100,0 & 11 & 100,0 \\
\hline \multirow[t]{4}{*}{9.} & Mengontrol BAB & & & & \\
\hline & a. Dengan bantuan & 0 & 0 & 0 & 0 \\
\hline & b.Mandiri & 11 & 100,0 & 11 & 100 \\
\hline & Total & 11 & 100,0 & 11 & 100,0 \\
\hline \multirow[t]{4}{*}{10.} & Mengontrol BAK & & & & \\
\hline & a. Dengan bantuan & 0 & 0 & 0 & 0 \\
\hline & b. Mandiri & 11 & 100,0 & 11 & 100,0 \\
\hline & Total & 11 & 100,0 & 11 & 100,0 \\
\hline
\end{tabular}


Temuan penelitian ini memperkuat pernyataan Brandt (2007 dikutip dalam Pinzon dkk, 2009) bahwa perbaikan status fungsional umumnya akan mencapai titik optimal pada pasien pasca stroke adalah pada saat bulan kedua hingga bulan keempat setelah menjalani terapi latihan fisik. temuan penelitian memperkuat pernyataan Soempeno (1993) bahwa apapun bentuk latihan fisik, selama dilakukan secara teratur dengan frekwensi antara 3-5 kali seminggu akan menghasilkan kebugaran fisik, kesehatan, maupun recovery yang lebih baik daripada hanya dilakukan 1 kali seminggu. Temuan penelitian ini juga memperkuat pernyataan Blackburn (2005) bahwa dampak positif latihan fisik yang dilakukan secara teratur akan bisa terlihat jika latihan fisik tersebut dilakukan 3-5 kali seminggu selama 2- 3 minggu.

Lebih banyaknya jumlah pasien yang mendapatkan perbaikan kemampuan fungsional optimum setelah menjalani terapi senam stroke $3 \mathrm{x}$ seminggu dibandingkan $2 \mathrm{x}$ seminggu disebabkan karena frekwensi terapi latihan fisik yang lebih sering menyebabkan jumlah massa otot meningkat lebih banyak. Akibatnya kekuatan fungsional yang diperoleh pasien menjadi lebih besar untuk melakukan aktifitas hidup harian menjadi lebih besar. Seperti dijelaskan oleh Auryn (2007 dikutip dalam Indriyati, 2009), stroke disebabkan oleh adanya sumbatan atau pecahnya pembuluh darah di otak yang menyebabkan jalur komunikasi ke daerah otak menjadi terhambat. Inilah yang menyebabkan terjadi penurunan kemampuan pasien untuk melakukan aktifitas hidup sehari-hari (activity of daily living) secara mandiri. Dengan sendirinya, latihan fisik yang diberikan pada pasien pasca stroke terlebih dahulu ditujukan untuk memancing kembali saraf-saraf yang rusak agar pulih terlebih dahulu, baru dilanjutkan dengan peningkatan kekuatan otot. Frekwensi dan durasi latihan fisik yang relatif pendek atau jarang menyebabkan proses pemulihan kekuatan otot tidak berjalan maksimal.

Data pada Tabel 5 memperlihatkan bahwa hasil uji statistik diperoleh nilai $p$ value $=0,198$. Ini mengandung arti bahwa pada alpha $5 \%$ perbedaan peningkatan kemampuan fungsional pasien antara pasien antara yang mengikuti terapi senam stroke $2 \mathrm{x}$ seminggu dengan yang $3 \mathrm{x}$ seminggu tidak signifikan.

Tabel 5. Perbedaan Peningkatan Kemampuan Fungsional Pasien Pasca Stroke Antara Yang Menjalani Terapi Senam Stroke 2x Seminggu Dengan 3x Seminggu

\begin{tabular}{lcccccc}
\hline $\begin{array}{c}\text { Kemampuan } \\
\text { Fungsional pasien }\end{array}$ & Median & Minimum & Maksimum & P-value & N \\
\hline $\begin{array}{l}\text { Senam stroke } \\
\text { seminggu }\end{array}$ & 5 & 5 & 15 & 0,198 & 11 \\
$\begin{array}{l}\text { Senam stroke } \\
\text { seminggu }\end{array}$ & $3 \mathrm{x}$ & 10 & 5 & 15 & & 11 \\
\hline
\end{tabular}

Tidak signifikannya peningkatan kemampuan fungsional pasien antara pasien yang mengikuti terapi senam stroke $2 \mathrm{x}$ seminggu dengan yang $3 \mathrm{x}$ seminggu dalam penelitian ini tercermin dari tidak berbedanya jenis aktifitas hidup harian yang dapat dilakukan secara mandiri oleh kelompok pasien yang telah menjalani terapi senam stroke $2 \mathrm{x}$ seminggu dengan $3 \mathrm{x}$ seminggu. Peningkatan kemampuan fungsional untuk melakukan aktifitas hidup harian pada kedua kelompok tersebut samasama terjadi pada 5 jenis aktifitas hidup harian yaitu (1) makan, (2) aktifitas di toilet, (3) berjalan di permukaan datar, (4) naik turun tangga, dan (5) berpakaian. Peneliti menduga bahwa Perbedaan frekwensi latihan yang terlalu tipis antara kedua kelompok tersebut ( $2 \mathrm{x}$ dan $3 \mathrm{x}$ seminggu), serta durasi terapi yang terlalu singkat (hanya $4 \mathrm{x}$ seminggu atau 1 bulan) menyebabkan perbedaan yang nyata 
kemampuan fungsional pasien pada kedua kelompok tersebut nyaris tidak terlihat.

\section{KESIMPULAN DAN SARAN}

Terapi senam stroke terbukti efektif untuk memperbaiki kemampuan fungsional pasien paska stroke iskemia, baik yang dilakukan $2 \mathrm{x}$ seminggu maupun yang dilakukan $3 \mathrm{x}$ seminggu. Akan tetapi, perbedaan peningkatan kemampuan fungsional yang terjadi pada kelompok pasien yang menjalani terapi senam stroke $2 \mathrm{x}$ serta $3 \mathrm{x}$ seminggu tersebut secara statistik tidak signifikan.

Berdasarkan temuan penelitian di atas, menyarankan agar terapi senam stroke diterapkan 3x seminggu dan panduan pelaksanaannya dibuatkan dalam bentuk SOP. Selanjutnya, meningkatkan durasi waktu terapi senam stroke agar sesuai dengan yang diterapkan yaitu 12 minggu (3 bulan) dan frekwensinya antara 3-5 kali seminggu untuk memastikan bahwa seluruh pasien mendapatkan peningkatan kemampuan fungsional yang optimum.

\section{DAFTAR PUSTAKA}

Anggleni, Titis. (2010). Faktor-faktor yang Berhubungan Dengan Kepatuhan Klien Pasca Stroke Dalam Mengikuti Rehabilitasi di Instalasi Rehabilitasi Medik RSUP M Djamil Padang. Skripsi. Padang : PSIK FK Unand

Boersma,et al., (nd). The Effects of Aerobic Exercise on functional recovery Post Stroke as Defined by the ICF: A Systematic Review. Diakses dari http://www.medscape.org, diperoleh tanggal 20 Agustus 2011

Blackburn, Gordon. (2005). Aerobic Exercise, direkomendasikan oleh The Cleveland Clinic. Diakses dari http://www.clevelandclinic.org, diperoleh tanggal 20 Agustus 2011.

Berwald, J. M., (2007). Neurological Encyclopedia: Exercise, direkomendasikan oleh Answer Coorporation. Diakses dari http://www.answers.com, diperoleh tanggal 14 Agustus 2011
Indriyati. (2009). Hubungan Activity Of Daily Living ( $A d l)$ Berdasarkan Indeks Barthel Dengan Tingkat Depresi Pada Pasien Stroke Di Bangsal Anggrek 1 Rumah Sakit Dr. Moewardi Surakarta. Skripsi S1 Keperawatan Fakultas Ilmu Keperawatan Universitas Muhamadiyah Surakarta

Pang, et al., (2006). The use of aerobic exercise training in improving aerobic capacity in individuals with stroke: a meta-analysis. Clinical rehabilitation. Diakses dari http://stroke.ahajournals.org. diperoleh 25 Agustus 2011

Parjoto, dkk. (1994). Aktivitas Fungsional dan Rekreasi. Surakarta: AKFIS Surakarta Depkes RI

Pinzon, Rizaldy; Asanti, Laksmi; Suginato, Kriswanto Widyo. (2009). Status Fungsional Pasien Non Hemoragik Pada Saat Keluar Rumah Sakit. Majalah Kedokteran Damianus. Vol 8, No 1. Hal: 27-30

Soegiarto, B. dkk (2004). Panduan Latihan Uji Jasmani Dan Peresepannya. Jakarta: EGC

Soeharto, Imam. (2002). Serangan Jantung dan Stroke Hubungannya dengan Lemak dan Kolesterol. Jakarta : PT Gramedia Pustaka Utama

Soemaryanti. (2005). Aktifitas Terapi. Publikasi Departemen Pendidikan Nasional Direktorat Jenderal Manajemen Pendidikan Dasar Dan Menengah Direktorat Pembinaan Sekolah Luar Biasa

Soempeno, dkk. (1993). Kesehatan Olahraga. Pendidikan Pelatih Program Dasar Klub Jantung Sehat, 28 - 29 agustus, Dinas Kesehatan Propinsi DIY, Yogyakarta.

Soeparman. (2004). Panduan Senam Stroke. Jakarta : Puspawara

Sutrisno, A. (2007). Stroke? You Must Know Before You Get It. Jakarta : PT Buana Printing

Widyatama, Arie. (2008). Penatalaksanaan Terapi Metode Motor Relearning Programme pada Kondisi Hemiparese 
Sinistra Post Stroke Non Haemoragic di RSUD Sukoharjo. KTI. Surakarta: Program Studi Fisioterapi FIK UMS

Widiyanto. (April 2009). Terapi Gerak Bagi Penderita Stroke. Medikora Vol. V

Wirawan, R. P. (Februari 2009). Rehabilitasi Stroke pada Pelayanan Kesehatan Primer. Majalah Kedokteran Indonesia. Vol.59. No. 2

Yulinda, Wina. (2009). Pengaruh Empat Minggu Terapi Latihan Pada Kemampuan Motorik Penderita Stroke Iskemia Di RSUP H. ADAM MALIK. KTI. Medan: FK USU 